\title{
ARTIGOS
}

\section{Grupo de estudos em Intermulticulturalidade e Formação de Professores(as) - GEIFOP}

\begin{abstract}
RESUMO: O texto apresenta as principais características do Grupo de Estudos em Intermulticulturalidade e Formação de Professores(as) (GEIFoP). Sua estrutura contempla os elementos constantes das apresentações dos grupos participantes do III Simpósio de Grupos de Pesquisa sobre Formação de Professores no Brasil, realizado de 3 a 4 de outubro de 2016, em Guarulhos SP. O grupo, iniciado em 2007, atua em três frentes: relações entre questões intermulticulturais e formação inicial e continuada de professores, enfatizando a discussão dos saberes docentes; relações intermulticulturais no currículo em ação; processos de aprendizagem profissional da docência, especialmente dos iniciantes. As pesquisas e intervenções realizadas pelo grupo impactam o currículo em ação nos anos iniciais do ensino fundamental, da educação de jovens e adultos e do ensino superior, assim como a formação de professores desses e para esses níveis e modalidade de ensino, tendo em vista a abordagem de questões intermulticulturais.
\end{abstract}

PALAVRAS-CHAVE: Formação de professores. Professores iniciantes. Currículo em ação. Intermulticulturalidade.

\section{Group of Studies in intermulticulturalty and teacher training}

\begin{abstract}
The text presents the main characteristics of the Study Group on Intermulticulturality and Teacher Education (GEIFoP). Its structure includes the elements contained in the presentations of the groups participating in the III Symposium of Research Groups on Teachers' Education in Brazil, held in October from 3rd through 4th, 2016, in Guarulhos, SP. The group, initiated in 2007, works on three fronts: relations between intercultural issues and initial and continuing teacher education, emphasizing the discussion of the teaching knowledge; intercultural relations in the curriculum in action; professional learning processes, especially for beginners. The research and interventions carried out by the group impact the curriculum in action in the initial years of elementary education, youth and adult education, and higher education, as well as the education of teachers for these levels and modality of education, concerning intercultural issues.
\end{abstract}

KEY-WORDS: Teacher education. Beginning teachers. Curriculum in action. Intermulticulturality. 


\section{autêntica}

DOI https://doi.org/10.31639/rbpfp.v10i18.195

\section{INTRODUÇÃO}

Este texto está estruturado de forma a contemplar os elementos presentes nas apresentações dos grupos participantes do III Simpósio de Grupos de Pesquisa sobre Formação de Professores no Brasil, realizado de 3 a 4 de outubro de 2016, na cidade de Guarulhos SP. Assim, compõe-se de cinco seções, a saber: ementa do grupo de pesquisa, na qual se insere a construção de sua trajetória teórica e seu tempo de existência; delineamento das linhas de pesquisa; pesquisas realizadas e em andamento, temáticas centrais abordadas pelo grupo e principais metodologias de pesquisa utilizadas; principais publicações do grupo de pesquisa e síntese de seus principais resultados. Por fim, são tecidas considerações adicionais julgadas pertinentes à trajetória do grupo.

\section{EMENTA, TEMPO DE EXISTÊNCIA E CONSTRUÇÃO DA TRAJETÓRIA TEÓRICA DO GRUPO DE PESQUISA}

Esta seção oferece as seguintes informações preliminares do grupo: sua ementa, tal como está expressa no Diretório dos Grupos de Pesquisa do CNPq; um breve histórico desde sua criação até os dias atuais; e sua trajetória teórica.

\subsection{EMENTA}

O GEIFoP atua em três frentes: a das relações entre questões intermulticulturais e formação inicial e continuada de professores, especialmente os que atuam nos anos iniciais do ensino fundamental, com ênfase na discussão dos saberes docentes; a das relações intermulticulturais ocorridas no currículo em ação, preferencialmente dos anos iniciais do ensino fundamental, ou de outros níveis de ensino, assim como em contextos não escolares; e a dos processos de aprendizagem profissional da docência, em especial na fase de ingresso na carreira. As pesquisas e intervenções realizadas pelo grupo impactam o currículo em ação nos anos iniciais do ensino fundamental, da educação de jovens e adultos e do ensino superior, assim como a formação de professores desses/para esses níveis/modalidade de ensino, tendo em vista a abordagem de questões intermulticulturais. O grupo tem enfatizado a perspectiva de anúncio de possibilidades consideradas bem sucedidas, em vez do diagnóstico/constatação de problemas enfrentados na realidade educacional.

\subsection{TEMPO DE EXISTÊNCIA DO GRUPO}

O GEIFoP é o sucedâneo do GEAD (Grupo de Estudos sobre Aprendizagem da Docência) cujo funcionamento se deu entre os anos de 2003 a 2007, pautado teoricamente na epistemologia da prática, sob a liderança da Profa. Emília Freitas de Lima. Dele resultaram várias dissertações, teses, pesquisas de IC e de outras bolsas de pesquisa no âmbito da UFSCar, assim como outras publicações em periódicos e capítulos de livros. Destaca-se a publicação do livro Sobrevivências no Início da Docência: LIMA, Emilia Freitas de (Org.). Sobrevivências no Início da Docência. Brasília: Liber Livros, 2006.

O aprofundamento de estudos da líder do GEAD - inclusive em pós-doutoramento - na abordagem intermulticultural, gerou a necessidade adequar o grupo a essas novas bases teórico-conceituais, dando origem, em 2007, ao 'Grupo de Estudos em Intermulticulturalidade e Formação de Professores(as)'.

Este também tem como líder a Profa. Emília Freitas de Lima (UFSCar) e como vice-líder o Prof. André Luiz Sena Mariano (UNIFAL). Envolve outros cinco pesquisadores vinculados à UFSCar e à UFSC e atualmente conta com seis estudantes de pós-graduação, entre mestrandos (mestrado acadêmico) e doutorandos. 


\subsection{CONSTRUÇÃO DA TRAJETÓRIA TEÓRICA DO GRUPO}

Em seus primeiros estudos, o GEIFoP (Grupo de Estudos em Interculturalidade e Formação de Professores) assumia uma abordagem que ficou conhecida como multiculturalismo crítico. Em que pese a polissemia em torno do tema, o grupo nunca teve foco nas discussões alusivas as essas diferenças epistemológicas. A despeito de reconhecer que a obra de McLaren (1997), durante muito tempo, era citada sempre como aquela que trazia as quatro definições possíveis para o tema, o grupo reconheceu e já assumiu o pressuposto crítico e suas primeiras publicações e trabalhos foram desenvolvidos a partir dessa premissa.

Para McLaren (1997), o multiculturalismo crítico reconhece as diferenciações e desigualdades que são estabelecidas em termos de raça/etnia, classe social e gênero através de artefatos provenientes de relações de poder e procura transformar as relações sociais nas quais os significados são gerados. Para tanto, o autor defende que não basta ter a diversidade como a meta a ser atingida, ela é, ao contrário disso, um recurso humano disponível e que está presente no mundo; essa diversidade deve ser o elemento balizador na formulação de políticas públicas e na busca por justiça social.

Nessa seara, Kincheloe (1997) nos ajuda a compreender que vivemos em um mundo inescapavelmente multicultural, ou seja, constituído por várias culturas. Porém, algumas pessoas e/ou grupos tendem a ignorar essa multiculturalidade, procurando reconhecer no mundo uma perspectiva de homogeneização cultural. O autor afirma, peremptoriamente, que não importa a nossa resposta a isso e mesmo o nosso silêncio para a diversidade, pois ela continuará existindo; negar a diversidade cultural no plano teórico, como várias vertentes o fazem, não implica o seu apagamento no plano das relações reais entre os seres humanos e os diversos grupos sociais.

Essa diversidade traz à tona a reflexão acerca da diferença. Para McLaren (1997):

O multiculturalismo de resistência também se recusa a ver a cultura como não-conflitiva, harmoniosa e consensual [...] Ele tem de estar atento à noção de 'diferença'. Diferença é sempre um produto da história, cultura, poder e ideologia. A diferença sempre ocorre entre dois grupos e entre muitos grupos e deve ser compreendida em termos das especificidades de sua produção. O multiculturalismo questiona a construção da diferença e identidade em relação a uma política radical (MCLAREN, 1997, p. 123-4).

A perspectiva crítica reconhece o profundo entrelaçamento que há nas discussões alusivas à identidade, diferença e cultura. Tal reconhecimento leva a análises que procuram, dentro do possível, dar conta daquilo que autores como Cuche (2002) e Eagleton (2010) afirmam ser um dos conceitos mais complexos e escorregadios das ciências humanas e sociais: o de cultura. Isso porque, de acordo com os autores, além das tensões que se colocam no embate teórico e, sobretudo, prático para as definições culturais, ele é um conceito que serve, ao longo do tempo, a variados e divergentes fatos e coisas. Se, em seu início, a cultura foi considerada como a atividade relativa ao cultivo de terras e animais, hoje, além dessa acepção, é possível reconhecer a cultura como o refinamento do espírito e, outrossim, como o estabelecimento do modo de vida um povo, uma sociedade.

Um autor que tem contribuído para a problematização da ideia de cultura como um modo de vida de um povo, sociedade ou grupo é Raymond Williams (1979; 1992). Precursor do materialismo cultural, o autor permite estabelecer compreensões que reconheçam a imbricação entre a dimensão subjetiva e a objetiva 


\section{autêntica}

DOI https://doi.org/10.31639/rbpfp.v10i18.195

das relações humanas. Há a assunção de que os elementos culturais disponíveis são os mesmos a todos os seres humanos no interior de um mesmo grupo, porém a significação que cada um faz é idiossincrática. Por mais objetivos, concretos, que sejam os elementos culturais, sua apropriação e ressignificação são, sempre, subjetivas e mediadas pela experiência.

Nesse sentido, o autor afirma que a experiência manifestada em consciência prática - algo que diz respeito àquilo que o homem vive, de fato, em seu cotidiano - impõe o reconhecimento de não existir uma cultura a priori, mas sim práticas culturais que se manifestam no cotidiano concreto. O homem se faz produtor e reprodutor de cultura a partir das relações sociais estabelecidas na prática; isso coloca a grande tarefa para aquele/a que procura estudar a dimensão cultural da vida humana: a de ter suas análises balizadas, inexoravelmente, pela prática.

O reconhecimento desse modo de vida estabelecido pela e a partir da prática implicou, aos estudos desenvolvidos pelo GEIFoP, a procura de um novo direcionamento. Longe de entrar em embates relativos ao melhor termo a ser utilizado na compreensão das práticas culturais e escolares, o grupo percebia que o termo multiculturalismo apresentava algumas fragilidades.

Assim, procurou uma nova diretriz aos seus estudos, algo que permitisse compreender esses modos de vida e as possíveis relações estabelecidas entre eles. O encontro com o conceito de interculturalidade permitiu que o GEiFoP encontrasse diretrizes mais adequadas às suas investigações. Havia um imperativo de compreender mais do que a existência de um mundo formado por várias culturas que se fazem presentes nas unidades escolares. Era preciso entender a relação entre essas culturas. Em Candau (2005), ao discorrer sobre os limites do multiculturalismo e propor a adesão a uma perspectiva de interculturalidade, o grupo encontrou essa nova diretriz.

A autora defende que:

Consideramos o interculturalismo como um enfoque que afeta a educação em todas as suas dimensões, favorecendo uma dinâmica de crítica e autocrítica, valorizando a interação e a comunicação recíprocas entre diferentes sujeitos e grupos culturais.

A interculturalidade orienta processos que têm por base o reconhecimento do direito à diferença e a luta contra todas as formas de discriminação e desigualdade social. Tenta promover relações dialógicas e igualitárias entre pessoas e grupos que pertencem a universos culturais diferentes, trabalhando os conflitos inerentes a essa realidade. Não ignora as relações de poder presentes nas relações sociais e interpessoais. Reconhece e assume os conflitos, procurando as estratégias mais adequadas para enfrentá-los (CANDAU 2005, p. 31-2).

Mais do que a simples constatação de vivermos em um mundo inescapavelmente multicultural, era preciso lançar olhar para as formas de interação entre as diferentes culturas. Interações que ocorrem desde o espaço escolar e não se fazem sem tensões, disputas e dissensos. Não basta reconhecer a existência de várias culturas, pois, para Candau, faz-se mister buscar a construção de práticas que, entre outras coisas, articulem, resgatem e promovam o diálogo intercultural.

Todavia, o grupo reconhece que esse diálogo apresenta o imperativo nevrálgico às discussões multiculturais, a saber: a tensão entre universalismo e relativismo. No que tange a isso, recentemente, o GEIFoP tem se 
aproximado das discussões da filósofa espanhola Adela Cortina. Andrade (2006), estudioso das obras da autora citada, advoga que ela, a partir de seus pressupostos habermasianos, propõe um equilíbrio entre os elementos denominados "ética de máximos" - relativos àquilo que pode trazer felicidade e, portanto, vivido num plano subjetivo - e "ética de mínimos" - aquilo que pode ser considerado justo e, portanto, pauta a organização e a construção de um mundo mais democrático.

Andrade, ao aproximar a discussão de Cortina da educação intercultural, elucida acerca dessa tensão. De acordo com ele,

[...] o primeiro a fazer é evitar a cilada de um universalismo exacerbado, no qual uma cultura - geralmente a da classe dominante - é tomada como a única possível, a única correta, a única com estatuto de validade. Um universalismo exacerbado pode nos levar à uniformização e ao desrespeito às diferenças, que são o que de fato garante que uma sociedade seja plural. Sem respeito às diferenças, não há pluralidade possível (ANDRADE, 2006. p. 252).

E o autor acrescenta:

Por outro lado, deve-se igualmente recusar a cilada do relativismo radical que considera que tudo vale por igual. Esta perspectiva, que identifico como um diferencialismo inconsequente, não se sustenta diante de um questionamento mais profundo, pois não se pode afirmar, por exemplo, que o ideal de igualdade entre homens e mulheres tem o mesmo valor que o machismo. Existe uma hierarquia de valores que pode e deve orientar nossas preferências, nossas ações e, por isso mesmo, a prática educativa. Uma hierarquia de valores sempre será válida se - e somente se - respeitar a dignidade humana como algo fundamental e inegociável (ANDRADE, 2006, p. 252).

Assim, o GEIFoP, em termos de compreensão das práticas escolares e das tensões culturais que se colocam desde a escola básica perpassando os cursos de formação de professores, tem procurado auscultar as práticas e estratégias que funcionam como elementos potencializadores na busca de uma dignidade mínima a ser perseguida. Dessa forma, em suas pesquisas, mais que denunciar os fatores que impedem a ocorrência desse respeito à dignidade mínima inegociável, o grupo tem enveredado por uma perspectiva de anúncio de possibilidades consideradas bem sucedidas.

Com relação à concepção de "saberes docentes", tal como definido em Lima (2014), ela será empregada num sentido positivo, pois que traz em si a visão dos professores não mais como simples consumidores de saberes exógenos, gerados à sua revelia, mas como produtores de saberes a partir de / em sua prática profissional.

Apoiamo-nos em Gauthier et al. (2006, p. 302-3) que adotam uma posição nem cientificista nem reflexivista [sic], entendendo que os professores acionam saberes experienciais e saberes provenientes de sua formação profissional, bagagem certamente incompleta mas cujo peso não se pode desprezar. Sendo a prática pedagógica uma atividade complexa, é preciso que o professor construa uma certa ordem para poder lidar com ela, devendo, para tal, utilizar sua capacidade de emitir julgamentos. E, para julgar, é que ele tem de mobilizar diferentes tipos de saberes oriundos da experiência e da formação. Os autores defendem, então, que o papel do professor deve ser encarado muito mais como o de um agente prudente do que como o de um cientista ou de um técnico (p. 304). Assim, os saberes docentes seriam construídos e acionados envolvendo o plano da racionalidade. 


\section{autêntica}

DOI https://doi.org/10.31639/rbpfp.v10i18.195

Em suma, o(a) professor(a) padrão é alguém que deve conhecer sua matéria, sua disciplina e seu programa, que deve possuir certos conhecimentos das ciências da educação e da pedagogia, sem deixar de desenvolver um saber prático fundado em sua experiência cotidiana com os alunos (TARDIF ET AL., 1991, p.221).

\section{DELINEAMENTO DAS LINHAS DE PESQUISA}

São as seguintes as linhas de pesquisa que configuram o GEIFoP, suas respectivas ementas e palavras-chave:

\subsection{APRENDIZAGEM PROFISSIONAL DA DOCÊNCIA}

Ementa: Investigação de processos de aprendizagem profissional da docência, em especial na fase de ingresso na carreira.

Palavras-chave: Aprendizagem Profissional da Docência; Professores Iniciantes

\subsection{INTERMULTICULTURALIDADE E FORMAÇÃO DE PROFESSORES}

Ementa: Investigação de relações entre questões intermulticulturais e formação inicial e continuada de professores dos anos iniciais do ensino fundamental.

Palavras-chave: Intermulticulturalidade; Formação de Professores

\subsection{INTERMULTICULTURALIDADE, CURRÍCULO E ESTUDOS CULTURAIS}

Ementa: Investigação de relações intermulticulturais ocorridas no currículo em ação, preferencialmente dos anos iniciais do ensino fundamental, ou de outros níveis de ensino, assim como em contextos não escolares.

Palavras-chave: Intermulticulturalidade; Currículo em Ação

\section{PESQUISAS, TEMÁTICAS CENTRAIS E PRINCIPAIS METODOLOGIAS DE PESQUISA}

Ao longo de sua trajetória, o grupo tem realizado pesquisas privilegiando determinadas temáticas e servindo-se de metodologias, conforme se explicita a seguir.

\subsection{PESQUISAS}

As principais pesquisas desenvolvidas pelo GEIFoP são:

\subsubsection{ARTICULAÇÃO E DIVERSIFICAÇÃO DE ESPAÇOS FORMATIVOS DAS LICENCIATURAS.}

Descrição: Pesquisa-ação desenvolvida junto aos cursos de licenciatura oferecidos pela UFSCar, visando aprimorar os espaços de discussão já existentes e criar novos, com a participação de docentes, estudantes e técnico-administrativos envolvidos com as licenciaturas; contribuir para a articulação de ações que visem incorporar resultados decorrentes do desenvolvimento de outros projetos relacionados às licenciaturas na UFSCar; promover ações voltadas à diversificação dos espaços formativos dos licenciandos; e contribuir para a melhoria da formação de formadores de professores.

Integrantes: Emilia Freitas de Lima - Coordenadora; 1 doutoranda; 4 Técnicas em Assuntos Educacionais vinculadas à ProGrad/UFSCar; 1 Assessora Pedagógica, também vinculada à ProGrad/UFSCar.

Financiador: Coordenação de Aperfeiçoamento de Pessoal de Nível Superior - Auxílio financeiro (Programa Prodocência). 


\subsubsection{NECESSIDADES FORMATIVAS DE DOCENTES DO ENSINO SUPERIOR}

Descrição: Pesquisa de campo objetivando analisar as necessidades formativas de docentes recém-ingressos em uma universidade pública, como base para a formulação de política de formação continuada de docentes do ensino superior.

Integrantes: Emilia Freitas de Lima - Coordenadora; 2 doutorandos; 3 Técnicas em assuntos Educacionais vinculadas à ProGrad/UFSCar; 1 Docente da UFSCar, também vinculada à ProGrad/UFSCar.

\subsubsection{INTERMULTICULTURALIDADE, ENSINO E FORMAÇÃO DE PROFESSORES}

Descrição: Em sua primeira fase, a pesquisa teve como principal objetivo aprofundar teoricamente as relações entre Intermulticulturalidade, ensino e formação de professores e suas possíveis implicações no âmbito da educação escolar, com especial destaque para os anos iniciais do Ensino Fundamental, com base em autores como Peter McLaren, Henry Giroux, Stuart Hall, Cortesão \& Stoer, Gimeno Sacristan, Michael Apple, entre outros. Na segunda fase, a pesquisa, tendo como base os conceitos de cultura, intermulticulturalidade, cultura de referência dos alunos, cultura da escola e pedagogia culturalmente relevante, pretende compreender e intervir na aprendizagem profissional docente, por meio de projetos envolvendo temas transversais. O projeto inclui o levantamento de dados (tipo survey) acerca da compreensão e uso pedagógico de conceitos ligados às questões inter/multiculturais, bem como uma pesquisa colaborativa envolvendo formação continuada em uma escola estadual de ensino fundamental (anos iniciais).

Integrantes: Emilia Freitas de Lima - Coordenadora; 8 pós-graduandos (mestrado acadêmico e doutorado); 03 graduandos (1 bolsista IC e 2 bolsistas treinamento).

Financiador(es): Fundação de Amparo à Pesquisa do Estado de São Paulo - Bolsa; Pró-Reitoria de Extensão - Bolsa; CNPq - Bolsa

\subsection{TEMÁTICAS CENTRAIS DE PESQUISA}

O grupo vem enfocando prioritariamente a formação continuada e a aprendizagem profissional da docência, sobretudo de professores iniciantes, assim como o currículo em ação e suas relações com a formação docente, tendo como base teórica a intermulticulturalidade e os saberes docentes.

\subsection{PRINCIPAIS METODOLOGIAS DE PESQUISA UTILIZADAS}

O GEIFoP tem trabalhado na perspectiva da pesquisa qualitativa, com a utilização de survey, análise de falas dos participantes e pesquisa-ação. Têm sido usados, como instrumentos de coleta de dados, as entrevistas, o questionário, a observação participante e a análise documental.

\section{PRINCIPAIS PUBLICAÇÕES DO GRUPO DE PESQUISA E SÍNTESE DE SEUS PRINCIPAIS RESULTADOS}

Algumas das publicações geradas a partir das pesquisas e intervenções realizadas pelo grupo, assim como uma breve análise de seus principais resultados, é o que se explicita nesta seção.

\subsection{PRINCIPAIS PUBLICAÇÕES}

CORSI, Adriana Maria; LIMA, Emilia Freitas de. Práticas pedagógicas no Ensino Fundamental na perspectiva do multiculturalismo crítico. Currículo sem Fronteiras, v. 10, p. 158-182, 2010. 


\section{autêntica}

DOI https://doi.org/10.31639/rbpfp.v10i18.195

GALIZIA, Fernando S.; LIMA, Emilia Freitas de. Ensino superior de Música: levantamento e análise da produção veiculada na Revista da Abem (1992-2013). Revista da ABEM - Associação Brasileira de Educação Musical, v. 22, p. 77-94, 2014.

GALIZIA, Fernando S.; LIMA, Emília Freitas de. Conhecimento na perspectiva intercultural: um estudo no ensino superior de música. Revista e-Curriculum (PUCSP), v. 16, p. 60-81, 2018.

LIMA, Emilia Freitas de. A construção de práticas pedagógicas inter/multiculturais no ensino fundamental e os saberes docentes. Revista Diálogo Educacional (PUCPR. Impresso), v. 14, p. 395-414, 2014.

LIMA, Emilia Freitas de. A formação inicial de professores e a didática na perspectiva inter/multicultural. Educação (UFSM), v. 34, p. 165-178, 2009.

LIMA, Emilia Freitas de. Análise de necessidades formativas de docentes ingressantes numa universidade pública. Revista Brasileira de Estudos Pedagógicos RBEP-INEP, v. 96, p. 343-358, 2015.

LIMA, Emilia Freitas de. Apontamentos sobre ensino e formação de professores intermulticulturais. SérieEstudos (UCDB), v. 27, p. 65-81, 2009.

LIMA, Emilia Freitas de. Em defesa da didática intercultural: apontamentos sobre um marco de referência. In: ROMUALDO, Claudio; GIROTTI, Márcio Tadeu; ZUIN, Poliana Bruno. (Org.). Diálogos em didática: tecendo histórias sobre o ensinar e o aprender. 1ed.São Paulo: Ideias e Letras, 2016, v. 1, p. 43-60.

LIMA, Emilia Freitas de. Saberes docentes e práticas pedagógicas inter/multiculturais: tecendo relações. In: DALBEN, A.; DINIZ, J.; LEAL, L.; SANTOS, L.. (Org.). Convergências e tensões no campo da formação e do trabalho docente: didática, formação de professores, trabalho docente. 1ed. Belo Horizonte: Autêntica, 2010 , v. 1, p. 354-374.

LIMA, Emilia Freitas de; MARIANO, André Luiz Sena. Uma aproximação à interculturalidade nas práticas pedagógicas escolares: qual o lugar dos saberes docentes?. In: VERA MARIA CANDAU. (Org.). Interculturalizar, descolonizar, democratizar: uma educação “outra"?. 1ed. Rio de Janeiro: 7 Letras, 2016, v. 1, p. 322-340.

MARIANO, André Luiz Sena; LIMA, Emilia Freitas de. A pesquisa sobre o início da docência a partir da ANPEd e do ENDIPE. In: REALI, A.M.M.R; MIZUKAMI, M.G.N.. (Org.). Desenvolvimento profissional da docência: teorias e práticas. 1ed. São Carlos/SP: EdUFSCar, 2012, v. 1, p. 245-264.

MARIANO, André Luiz Sena; LIMA, Emilia Freitas de. A formação de professores e o início da docência: reflexões a partir da racionalidade crítica. In: COLARES, Maria Lília I. S.; XIMENES-ROCHA, Solange H.. (Org.). Aprendizagem da Docência: reflexões sobre os cursos de formação, a inserção profissional e as recentes pesquisas na área. Curitiba - PR: CRV, 2009, p. 87-99.

MARIANO, André Luiz Sena; LIMA, Emilia Freitas de. A dimensão intelectual do trabalho docente e o lugar do conhecimento escolar: do intelectual transformador à pedagogia histórico-crítica. Pesquiseduca, v. 09, p. 262-281, 2017. 
MÔNACO, Graziela; LIMA, Emilia Freitas de. A investigação sobre o currículo de ciências para a educação de jovens e adultos (EJA): diálogo com estudantes sobre os conhecimentos científico e popular. Enseñanza de las Ciencias, v. Extra, p. 1028-1032, 2013.

MÔNACO, Graziela; LIMA, Emilia Freitas de. Que conhecimentos sobre Ciências ensinamos na Educação de Jovens e Adultos e quais poderíamos ensinar?. Série-Estudos (UCDB), v. 32, p. 67-85, 2011.

PALOMINO, Thais Juliana; CORSI, Adriana Maria; LIMA, Emilia Freitas de. Problematizando diversidade e diferença: formação de profissionais da educação. In: SOUZA, M.H.A. de O.; GIL, M.S.C. de A.. (Org.). Diversificando caminhos da formação de professores na UFSCar. 1ed. São Carlos / SP: Compacta Gráfica e Editora, 2016, v. 1, p. 45-68.

REIFF-LOURENÇO Roberta B. de M.; LIMA, Emilia Freitas de. A TV em sala de aula: a leitura crítica de um desenho animado citado por alunos como preferido. In: MIZUKAMI, M. da G. N.; REALI, A. M. de M. R.. (Org.). Aprendizagem profissional da docência: saberes, contextos e práticas. $2^{a} e d$.São Carlos/SP: EDUFSCar, 2010, v. 1, p. 321-437. 


\section{autêntica}

DOI https://doi.org/10.31639/rbpfp.v10i18.195

\subsection{SÍNTESE DOS PRINCIPAIS RESULTADOS DO GRUPO DE PESQUISA}

O grupo tem contribuído de forma importante na formação de pós-graduandos - mestrandos e doutorandos, tendo também acolhido uma docente da UFU como pós-doutoranda. Vem divulgando os resultados de suas pesquisas em eventos nacionais e internacionais.

Destaque-se que, além de as pesquisas desenvolvidas no âmbito do grupo integrarem pós-graduandos, a título de aprendizagem de pesquisa, há inúmeras teses e dissertações, concluídas e em andamento, que contemplam suas linhas de pesquisa.

\section{CONSIDERAÇÕES ADICIONAIS}

No capítulo que elaboraram recentemente, Lima e Mariano (2016) analisando a produção de dissertações e teses oriundas do GEIFoP especificamente no que concerne à interculturalidade, encontraram como resultado geral que as professoras cujo trabalho fora pesquisado, apresentavam imensas dificuldades em traduzir na prática esse conceito, embora tivessem muito interesse em fazê-lo. Pensamos que a reprodução de parte das considerações finais de tal capítulo possa denotar um pouco de como vemos as relações entre interculturalidade e saberes docentes.

Também é importante frisar que o GEIFoP não adere a uma postura que só anuncia possibilidades sem que essas encontrem ancoradouro na realidade. Ao enfatizar o que a escola não consegue fazer com relação à temática e apresentar suas apostas teóricas e metodológicas, rechaça quaisquer perspectivas idealistas que advoguem que a tomada de consciência é elemento nevrálgico para a mudança do real.

Ao assumir a primazia da prática pedagógica como foco de análise, e construir, dentro do possível, caminhos para retornar a ela de maneira crítica e propositiva é que o grupo aposta na união indissociável entre metodologia, conteúdo e sensibilidade, tal qual o fez Lima (2009). Com isso, o grupo se posiciona contra correntes que defendem uma mudança de postura do professor e secundarizam o domínio do conteúdo. Pelo contrário, tal qual fora relatado em um dos estudos, uma abordagem intercultural requer domínios mais complexos de um assunto, pois exige buscar os nexos explicativos para problematizar aquele conhecimento. Consequentemente, esses nexos levam a outra postura metodológica e ao domínio da sensibilidade.

O acionamento da sensibilidade, aliado ao conteúdo e às metodologias, conduz-nos ao reconhecimento de que a educação, por ser uma prática cultural, é também uma prática de produção (WILLIAMS, 1979; 1992). Em outras palavras, a escolha do conteúdo a ser ensinado, aliado à forma como será ensinado é que ensejam a formação do tipo de aluno que se espera/deseja. E é nesse aspecto que, a nosso ver, reside a sensibilidade apregoada pelo GEIFoP: não é aquela discussão que se restringe ao discurso "se não posso ensinar, ao menos posso amar'; ao contrário, é o reconhecimento de que a forma pela qual um conteúdo é ensinado guarda íntima relação com a forma como os alunos tenderão a lidar com aquele assunto em seu cotidiano. Não se trata de uma aposta ingênua de que o conhecimento é elemento suficiente para mudar o mundo, mas trata-se de reconhecer que um mundo igualitário, justo, democrático passa pela - embora não se esgote na - forma como os conteúdos são acionados nos diversos níveis de ensino.

Por fim, outra aposta do GEIFoP é que essa sensibilidade não pode ficar a cargo das idiossincrasias de cada docente. Ela implica a formulação de políticas públicas que respeitem e valorizem a diversidade cultural. Não basta inserir professores sensíveis à temática no interior das escolas sem que, como contrapartida, haja a 


\section{autêntica}

DOI https://doi.org/10.31639/rbpfp.v10i18.195

garantia de uma carreira docente digna e justa, e de recursos das mais variadas ordens que oportunizem práticas pedagógicas pautadas pela interculturalidade.

Dessa forma, o GEIFoP não concorda em deixar a cargo de cada professor a decisão pelo trabalho nessa abordagem nem em criar mecanismos de imposição que obriguem os professores a aderirem. Isso porque a sensibilidade passa, entre outros aspectos, pela forma como conteúdos e metodologias são trabalhados na formação inicial e na continuada, mas também - e principalmente - pela "luta incessante para que a sociedade, por meio de seus governantes e formuladores de políticas públicas, se mostre sensível às demandas daqueles/as excluídos/as pela história dominante". (LIMA; MARIANO, 2016, p. 337-339).

\section{REFERÊNCIAS}

ANDRADE, Marcelo. Ética mínima e educação plural: em busca de fundamentos ético-filosóficos para uma educação intercultural. In: CANDAU, Vera (org.). Educação Intercultural e cotidiano escolar. Rio de Janeiro: 7Letras, 2006, pp. 238-255.

CANDAU, Vera. Sociedade multicultural e educação: tensões e desafios. In: (org.). Cultura(s) e educação: entre o crítico e o pós-crítico. Rio de Janeiro: DP\&A, 2005, pp. 13-37.

CUCHE, Denys. A noção de cultura nas ciências sociais. Bauru - SP: EDUSC, 2002.

EAGLETON, Terry. A ideia de cultura. São Paulo: Editora UNESP, 2010.

GAUTHIER, C. et al. Por uma teoria da Pedagogia: pesquisas contemporâneas sobre o saber docente. 2a ed. Ijuí: Ed. Unijuí, 2006.

KINCHELOE, Joe L. A formação do professor como compromisso político. Mapeando o pós-moderno. Porto Alegre: Artes Médicas, 1997.

LIMA, Emilia Freitas de; MARIANO, André Luiz Sena. Uma aproximação à interculturalidade nas práticas pedagógicas escolares: qual o lugar dos saberes docentes? In: CANDAU, Vera Maria. (Org.). Interculturalizar, descolonizar, democratizar: uma educação "outra"? 1ed. Rio de Janeiro: 7 Letras, 2016, v. 1, p. 322-340.

LIMA, Emilia Freitas de. Apontamentos sobre ensino e formação de professores intermulticulturais. SérieEstudos (UCDB). Campo Grande-MS, n. 27, p. 65-81, jan./jun. 2009.

MCLAREN, Peter. Multiculturalismo crítico. $3^{\text {a }}$ ed. São Paulo: Cortez, 1997.

TARDIF, M. LESSARD, C. e LAHAYE, L. Os professores face ao saber: um esboço de uma problemática do saber docente. Teoria e educação: Porto Alegre, n. 4, 1991.

WILLIAMS, Raymond. Cultura. São Paulo: Paz e Terra, 1992.

WILLIAMS, Raymond. Marxismo e Literatura. Rio de Janeiro: Zahar, 1979. 
